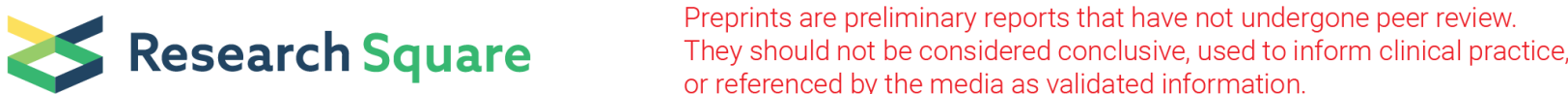

\section{Perspectives on a psychiatric outpatient service for immigrants and refugees in São Paulo, Brazil over a 15-year period.}

\author{
Luciana de Andrade Carvalho ( $\square$ lucarvalho03@gmail.com ) \\ Universidade de Sao Paulo Hospital das Clinicas \\ Laura Helena Andrade \\ Universidade de Sao Paulo Hospital das Clinicas \\ Patrícia Lin Ang \\ Universidade de Sao Paulo Hospital das Clinicas \\ Carmen Lucia de Albuquerque Santana \\ Universidade Federal de Sao Paulo \\ Paula de Vries Albertin \\ King's College London \\ Francisco Lotufo Neto \\ Universidade de Sao Paulo \\ Claudinei Eduardo Biazoli Junior \\ Universidade Federal do ABC
}

\section{Research article}

Keywords: Refugee, asylum seekers, immigrant, mental health, post-migration difficulties, psychiatric disorder, migration, São Paulo, service use

Posted Date: March 10th, 2020

DOI: https://doi.org/10.21203/rs.3.rs-15800/v2

License: (9) (1) This work is licensed under a Creative Commons Attribution 4.0 International License. Read Full License

Version of Record: A version of this preprint was published at International Journal of Social Psychiatry on June 20 th, 2021. See the published version at https://doi.org/10.1177/00207640211027207. 


\section{Abstract}

Background Immigrants and refugees have specific mental health needs. Studies of immigrant/refugee psychiatric patients in Latin America are scarce. This article presents the profile of patients from an outpatient psychiatric service in Sao Paulo (Brazil) and aims to better inform mental health service planning for immigrants and refugees.

Methods This was an exploratory study to characterize the sociodemographic and mental health profile of refugees and immigrants attending outpatient psychiatric service from 2003 to 2018. Chi-square tests and logistic regressions were used to examine the association of demographic variables, exposure to violence, and immigrant status with psychiatric diagnosis. Cluster analysis was used to identify subgroups within the sample.

Results A total of 162 immigrants and refugees referred to the service obtained treatment. Of these patients, $57.4 \%$ were men, $59.8 \%$ were refugees/asylum seekers, $51.9 \%$ were Black, $48.8 \%$ were single, $64.2 \%$ had ten years of education, and $57.4 \%$ were unemployed; the mean age of the sample was 35.9. Half of the sample (52.5\%) was exposed to violence. The most common diagnosis was depression (54.2\%), followed by PTSD (16.6\%). Approximately $34 \%$ of the participants sought psychiatric care within six months of arrival. Logistic regressions showed that men had lower odds of presenting with depression $(\mathrm{OR}=0.34)$. Patients with PTSD were more likely to be refugees $(\mathrm{OR}=3.9)$ and not have a university degree $(\mathrm{OR}=3.1)$. In the cluster analysis, a cluster of patients with PTSD included almost all Black refugee men exposed to violence. Most patients diagnosed with psychotic disorders were also Black refugee men.

Conclusion : Immigrants and refugees represent a vulnerable group. The majority of the sample was Black, refugee men, who were also more likely to present with PTSD. Future studies are needed to better understand issues in treatment adherence in relation to socioeconomic characteristics.

\section{Background}

International migratory flows have increased worldwide in recent decades. Current estimates suggest that there are 244 million international migrants globally. ${ }^{1}$ Most people migrate to countries in the Global North ${ }^{A}$, aiming for job opportunities. However, there is some migration among countries in the Global South, ${ }^{2}$ called South-South migration. This trend reflects the restrictions imposed by Northern countries on the entrance and permanence of immigrants in their territories and economic issues. In 2015, there were 90.2 million South-born immigrants living in another Southern country, while in the Global North, there were 85.3 million South-born immigrants. ${ }^{3}$

In migratory studies, it is important to distinguish between immigrants, refugees and asylum seekers because of different legal definitions and backgrounds. Immigrants, in general, are people who choose to migrate, usually for economic reasons. Refugees, on the other hand, fall under the category of forced displacement, since they leave their countries because of persecution and life-threatening situations. Asylum seekers are people who have applied for refugee status but are still waiting for the outcome of their application. The number of people undergoing forced displacement has increased in recent years. According to the United Nations High Commissioner for Refugees (UNHCR), 70.8 million people were displaced by the end of 2018. Of these, 13.6 million people became displaced just during $2018 .{ }^{4}$

As part of the South-South migration trend, immigration has also increased in Brazil. According to the 2010 national Census, the number of immigrants increased $53 \%$ compared to the data reported in the 2000 Census. ${ }^{5}$ The number of new entrances has also increased: there were 59,442 new registrations in $2010^{6}$ and 117,745 in $2015 .^{7}$

The number of refugees and asylum seekers in Brazil is also on the rise. In 2010 and 2018, there were 3,904 refugees and 11,231 refugees, respectively, in Brazil. ${ }^{8,9}$ The number of asylum seekers also increased dramatically - from 966 new requests in 2010 to 33,866 in 2017 and 80,057 in 2018. ${ }^{8,9}$ By the end of 2018, the majority of refugees in Brazil were from Syria (36\%), followed by the Democratic Republic of Congo (DRC) (15\%). ${ }^{9}$ The most common nationality of asylum seekers has been changing every year: in 2010, the majority of asylum seekers were Colombians; in 2013 and 2014, they were Haitians; and in 
2017 and 2018, they were Venezuelans. $8,9,10$ In Brazil, a person is considered a refugee when they are being persecuted due to their religion, nationality, ethnicity, political opinion, membership to a particular social group, or severe violation of human rights. ${ }^{11}$ Any foreigner can apply for refugee status in Brazil. This request is directed to the Brazilian Committee for Refugees (CONARE) to be evaluated. An interview at CONARE is scheduled to evaluate the asylum seeker's story and determine whether the person will be granted refuge or not. At the moment, this interview takes approximately 2 years to be scheduled. In the meantime, the person is allowed to have a social security number and work permit in Brazil. The majority of refugees and asylum seekers are located in the state of São Paulo. ${ }^{12}$ As of 2016, there were 2,582 refugees in the state of São Paulo, and $75.6 \%$ lived in the city of São Paulo, ${ }^{13}$ which is the richest and largest city in Brazil, with many job opportunities and a high level of industrialization.

There are public shelters in the city of São Paulo that are specific for immigrants and refugees, but one cannot stay in most places for more than 3 months. Shelters for the Brazilian homeless population in São Paulo can also be used by immigrants and refugees, also with a limited time of stay. When public shelters are not available (or someone did not adapt to them, or they had to leave), other forms of temporary housing are churches or mosques that allow migrants to sleep in their common areas. It is expected that migrants start working as soon as possible and support themselves integrally. Most jobs have low pay and require a low educational level.

Immigrants and refugees are a vulnerable group. Many stressors can be identified in different stages of migration. Once in a new country, they can be confronted with differences such as language and culture. They also have to deal with losses of significant relationships and social support networks. Some immigrants also face difficulties with documents and paper work and experience discrimination and social exclusion. ${ }^{14}$ An uncertain visa status and a prolonged asylum procedure are associated with a higher prevalence of mental disorders and more severe symptoms. ${ }^{15,16,17}$

Differences in mental health status between immigrants and refugees have been examined. Some studies support that refugees have higher rates of depressive disorders and post-traumatic stress disorder (PTSD) than non-refugees ${ }^{18,19,20}$ and poorer mental health in general. ${ }^{21}$ Exposure to traumatic events can also be higher for refugees than for immigrants, which is associated with higher rates of PTSD. ${ }^{22,23}$

Immigrants usually have lower rates of common mental disorders than locals at arrival; however, over time, their rates become similar to the local population. ${ }^{24}$ However, for psychotic disorders there is a wide rage of literature describing higher rates among immigrants compared to the local population. Studies are mostly from Global North countries ${ }^{25}$, in which locals are mostly White. Ethnicity is taken into account, since minority ethnic groups present higher incidence of psychotic disorders than locals (1.5-3.0 times) ${ }^{25}$ and differences are described between different ethnic groups. For instance, in the UK, compared to the local population, psychosis risk is 1.5 times higher for White migrants, while for Pakistani and Bangladeshi people have 2-4 times increased risk and for Black Caribbean and African groups the risk is 10 times higher. ${ }^{26}$

Understanding gender differences in migrants' and refugees' mental health is an emerging and crucial task. Refugee and asylum-seeking women are more prone to gender-based violence. ${ }^{27}$ Moreover, higher prevalences of mental disorders, particularly depression and PTSD, are reported in women. ${ }^{28,29}$ Additionally, women who are refugees or asylum seekers have higher rates of these disorders than non-refugees. ${ }^{30,31,32}$

Though widely discussed in Europe and North America, immigrant and refugee health is a field of very recent development in Brazil, with few publications and expertise.

In Brazil, access to healthcare is universal and free of charge, including for immigrants and refugees. ${ }^{33}$ In addition to universality of coverage, the principles of the national healthcare system (Sistema Único de Saúde - SUS) include equity and integrality of care, which is meant to be organized by territorial distribution and on primary, secondary and tertiary care facilities. Hence, immigrants and refugees are supposed to access the same general and mental health services offered to the population. However, international migrants face specific barriers for accessing health services, such as language, lack of 
information and other structural barriers, which justifies directed policies and implementation of specialized secondary and tertiary services. ${ }^{34}$

In 1997, an outpatient psychiatric service for immigrants, refugees and asylum seekers was created as part of the Brazilian public health SUS system. The aim of the service was to facilitate access to mental health care and provide long-term care for immigrants, refugees, and asylum seekers in Sao Paulo. The service, called Programa de Psiquiatria Social e Cultural (ProSol), was developed based on participatory action research through a community - campus ${ }^{35}$ partnership between the Institute of Psychiatry of Universidade de Sao Paulo and the Caritas Refugee Reference Center (CRRC), a program linked to Caritas, which is an international Catholic non-governmental organization (NGO) of humanitarian help. The CRRC provides legal, documentational and social aid, orientations, referrals and psychological support for immigrants, refugees, and asylum seekers. The São Paulo State Secretary of Health supported the creation of the project. To date, ProSol is the only tertiary service specialized in immigrant and refugee psychiatric care in the country.

Given the uniqueness of the ProSol service, we aim to present the profile of all patients who used the service between 2003 and 2018. In fact, quite a few studies describe the profile of immigrants and refugees attending psychiatric specialized care, but the existing literature comes primarily from Global North countries. ${ }^{36,37}$ Moreover, we aim to discuss the challenges and possibilities of service planning and organization policies for delivering psychiatric care to immigrants and refugees in a highly complex and specialized context. As ProSol is the only psychiatric reference center for refugees and immigrants in Brazil, the characterization of this specific population can be useful for planning future research and policies and, ultimately, implementing services specialized in immigrants' and refugees' mental healthcare in the Global South.

\section{Methods}

To characterize the demographics and mental health profile of all refugee and immigrant patients attending the ProSol outpatient service from January 2003 to December 2018, a descriptive and exploratory study based on electronic and paperbased medical records was conducted.

All participants were registered on the local electronic database implemented in 2003. The following data were extracted from the electronic database: age at first consultation, sex, skin color, educational level, nationality, marital status, follow-up period (calculated as the difference between the dates of first and last consultation), and all prescribed medications. Further information was gathered from paper-based medical records, including the number of children, employment status at first appointment, housing situation at first appointment, date of arrival in Brazil, reason for migration, exposure to violence, service of referral, tobacco use, pain complaints, and ICD-10 psychiatric diagnoses on the last consultation.

Descriptive statistics for all the variables collected and for all participants were produced, and data visualization was implemented using a combination of different software (i.e., SPSS Statistics v. 17.0-Chicago II and R). Estimate proportions within subsamples were obtained with cross-tabulations. For all analyses, asylum seekers and refugees were considered one group, since most asylum seekers in our sample were clearly refugees who were not yet officially recognized. Since an exploratory investigation for potential associations was designed, a threshold of 0.05 for $p$-value (uncorrected for multiple comparisons) was applied for all tests. For the categorical variables, a set of Chi-square tests was performed. Furthermore, for diagnostic categories with a sufficient number of individuals, logistic regressions were performed to test the association between diagnosis and characteristics shown to be relevant in the literature (gender, exposure to violence, skin color, being a refugee). Finally, an unsupervised learning algorithm (k-means) was used to perform a cluster analysis to examine sub-group characteristics. The variables sex, skin color, refugee status, exposure to violence and ICD-10 psychiatric diagnosis were included. First, data were converted to numeric types, and the number of clusters was determined using an optimization approach. Hence, k-means was run for the optimized number of clusters (6), and each cluster profile was described.

\section{Results}




\section{Demographic and Socioeconomic Profile}

The total sample consisted of 162 patients, including 93 (57.4\%) men and 69 (42.6\%) women. This number represents all immigrants and refugees who used the service between 2003 and 2018. The largest ethnic group in the sample described their ethnicity as Black (51.9\%), followed by White (38.9\%).

Skin color and sex are summarized in Figure 1-A, and a significant difference was observed in the distribution (chi-square test, $\mathrm{p}=0.015$ ), indicating that men are predominantly Black and women are predominantly White in our sample. The histogram of the distribution of age at first consultation is shown in Figure 1-B (mean age: 35.9 +/- 11.9 years; median: 34 years). Regarding marital status, $48.8 \%$ were single, $21.6 \%$ were married, and $18.6 \%$ were divorced/separated/widowed; $43.8 \%$ had no children. Regarding education, $64.2 \%$ had at least ten years of formal education, with $32.1 \%$ having a complete or incomplete university degree. A total of $57.4 \%$ of the sample was unemployed; $36.4 \%$ were living in public shelters, and $9.9 \%$ were living with friends, family or churches as a favor. (Figure 1-C); thus, $46.3 \%$ of the sample was living in temporary housing.

\section{Migration Characteristics and Violence Exposure}

Refugees accounted for $38.3 \%$ of the sample, and asylum seekers accounted for $22.2 \%$ of the sample, for a total of $59.8 \%$. Concerning reasons for migration, approximately $33.3 \%$ migrated because of war, and $11.7 \%$ migrated because of political issues (information missing in $22.8 \%$ of the records). Regarding country of origin, $14.2 \%$ were from the Democratic Republic of Congo (DRC), and a similar percentage were from Colombia (13.6\%), followed by Nigeria (7.4\%) and Syria (6.7\%). Approximately $50 \%$ were from Africa, of which $28.4 \%$ were from the DRC; $29.6 \%$ were from Latin America, with $45.8 \%$ from Colombia; and $14.2 \%$ were from Asia/Middle East, of which $47.8 \%$ were from Syria and $17.4 \%$ from Iraq. Countries of origin are shown on the map in Figure 2. More than half of the participants were exposed to violence (52.5\%), and among those, $82.3 \%$ suffered violence prior to migrating. There is no evidence of an association between sex and violence exposure $(p=0.8)$.

\section{Service Use and Compliance}

The mean number of new patients per year (from 2003 to 2018) was 9.12. The number of new patients has been steadily growing: between 2003 and 2008, 35 patients were admitted; between 2009 and 2013, 47 patients were admitted; and from 2014 to 2018, 54 patients were admitted. Thirty-four percent sought psychiatric care within six months of arriving in Brazil, and $42.6 \%$ sought psychiatric care within twelve months. Approximately $12.3 \%$ sought care within five years after arrival. Data on the date of arrival in Brazil was missing in $23.5 \%$ of our sample. Forty-two percent did not spend more than three months in the service, and $21.6 \%$ spent between four and twelve months in the service. Only $13 \%$ stayed in the service for more than five years.

Patients were mostly referred by the CRRC (70.4\%), followed by a public shelter that only houses foreign women (7.4\%). Factors associated with having the first appointment within six months of arriving in Brazil were having post-traumatic stress disorder (PTSD) $(p<0.0001)$, being Black $(p=0.001)$, being a refugee $(p=0.022)$ and living in temporary housing $(p<0.0001)$. Men were more likely than women to drop out after three months $(p=0.018)$ and after six months $(p=0.049)$.

\section{Psychiatric Diagnosis}

Depression was the most frequent disorder (54.2\%; $9.9 \%$ mild, $24.7 \%$ moderate, $3.7 \%$ severe and $7.4 \%$ recurrent), followed by PTSD (16.6\%), psychotic disorders (13.6\%), anxiety disorders (12.3\%) and substance abuse disorders (9.3\%). Tobacco use was reported by $13 \%$ of the sample; $2.7 \%$ had no psychiatric diagnosis.

Over a third of the patients had comorbid disorders (35.8\%). The most frequent comorbidities were depressive disorder (F3233) and trauma-related disorders (F43.1-43.9), which accounted for $41.8 \%$ of cases of comorbidity and represented $14.8 \%$ of the total sample. 
Being a refugee $(p=0.004)$, living in temporary housing $(p=0.022)$, exposure to violence $(p<0.001)$, and first medical appointment within 6 months of arrival $(p<0.001)$ were associated with having PTSD.

Being Black $(p=0.004)$ and being male $(p=0.020)$ were associated with having a psychotic disorder $(p=0.004)$. Anxiety disorder (F41) was also associated with being Black $(p=0.010)$, being unemployed $(p=0.016)$, living in temporary housing $(p=0.044)$ and not being exposed to violence $(p=0.032)$. Depressive disorder was associated with being female $(p=0.007)$. Substance use was associated with being male $(p=0.008)$ and tobacco use $(p<0.001)$. Pain was a complaint among $42 \%$ of the sample $(n=68)$. Logistic regression results suggested that compared with men, women have increased odds of having depressive disorders ( $\mathrm{OR}=2.94, \mathrm{Cl} 95 \%$ 1.43-5.88). People with trauma-related disorders (F43) were eight times more likely to have been exposed to violence (OR= 8.1, CI95\% 2.9-22.1), three and a half times more likely to be refugees or asylum seekers $(\mathrm{OR}=3.5$, $\mathrm{CI} 95 \%$ 1.18-7.8) and approximately three times more likely to not have a university degree (OR=3.2, CI95\% 1.28-8.2). People with PTSD were sixteen times more likely to have been exposed to violence (OR=16.8, CI95\% 3.6-78.9), approximately four times more likely to be refugees or asylum seekers ( $\mathrm{OR}=3.9, \mathrm{Cl} 95 \% 1.18-12.76)$ and three times more likely to not have a university degree $(\mathrm{OR}=3.1, \mathrm{Cl} 95 \%$ 1.1-8.77).

\section{Cluster Analysis}

For six clusters, a purity measure of 0.85 was obtained. Most clusters mainly consisted of a single diagnostic category, with anxiety disorders distributed across different clusters. Depressive disorders were separated into two clusters based on sex. The cluster including patients with PTSD showed remarkable homogeneity, with almost all patients being Black refugee men with a history of exposure to violence. A cluster comprising patients with psychotic disorders was also homogeneous, with the majority of the cluster being Black refugee men. Finally, two clusters comprised anxiety disorders and other diagnostic categories.

\section{Medication and Hospitalization}

Antidepressants were the most prescribed medication (75.3\%), followed by antipsychotics $(27.2 \%)$ and benzodiazepines (16.6\%). No medication was prescribed in $12.3 \%$ of cases. Hospitalization in inpatient services at the same hospital was necessary for $8.6 \%(n=14)$ of all patients. Of these patients, $71.4 \%$ were hospitalized due to an acute psychotic episode.

\section{Discussion}

To the best of our knowledge, this is the first study describing the sociodemographic and psychiatric profile of a clinical sample of immigrants and refugees in Latin America. Although the total number of patients seen over 15 years is small $(n=162)$, the number of first appointments has grown exponentially. The small sample size is due to the fact that for the first 7 years, the service only received referrals from the CRRC; therefore, patients during this time period were mostly refugees and asylum seekers, and there were few of them in Brazil until the past decade. ProSol is a specialized psychiatric service in a tertiary hospital; therefore, only cases of higher complexity are referred for care.

It is important to consider that this is a psychiatric specialized service. When the service began, a very small number of people who were referred from the CRRC actually came to the service. In the beginning, a psychiatrist from the service stayed at the CRRC facility, developing a mental health department there. This process is described elsewhere. ${ }^{35,38}$

Since the main source of referrals was CRRC, we could expect the majority of patients to be refugees and asylum seekers (59.8\%). Our sample is mostly composed of single men of productive age (20-40 years) without children. According to the Brazilian Committee for Refugees, the majority of refugees and asylum seekers fit this profile. ${ }^{9}$

In cluster analysis, we found a high correlation between being male, Black and a refugee with having PTSD or a psychotic disorder. Using the intersectionality framework can be useful for understanding vulnerabilities associated with each of these identities. ${ }^{39}$ The issue of racism is particularly important in Brazil, with Black and White refugees having different experiences 
in integration and acceptance in Brazilian society. ${ }^{40}$ Therefore, more studies in Brazil are needed to investigate the complexity of multiple minority statuses and possible mental health outcomes.

Gender differences and diagnoses were found for depressive and psychotic disorders: women had increased odds of having depression compared to men, and men had increased odds of having a psychotic disorder compared to women. Systematic reviews and meta-analyses have confirmed that refugees are at substantially higher risk for having mental health problems than the general population. ${ }^{24,41}$ In our sample, PTSD was the only disorder that was found more frequently in refugees than in immigrants, which is consistent with literature data. ${ }^{21,22,23}$ The majority of our sample has been exposed to violence (52.5\%), especially before migration (82.3\%), with no differences in proportions between immigrants and refugees or between men and women. Having experienced violence was only related to PTSD and trauma-related disorders but not to other diagnoses. Nevertheless, we were not able to characterize the type of violence experienced (e.g., torture) to establish a correlation between specific traumatic events and PTSD. It was also not possible to investigate how many traumatic events people experienced, which would have been useful for exploring the concept of sequential traumatization. ${ }^{42}$

Our findings are consistent with the existing literature on increased rates of depression, chronic pain and other somatic complaints in refugees. ${ }^{24}$

Strong evidence shows that some groups of migrants have an elevated incidence of psychotic disorders after migration. Being Black and migrant have been previously associated with the development of psychotic disorders or episodes. ${ }^{43,44}$ The diagnosis of a psychotic disorder was associated with accessing the service within six months of arrival, as was PTSD.

The ProSol service accepts referrals from NGOs and public shelters since these are places that are close to the international migrant population. Immigrants and refugees face difficulties in accessing Brazilian public health services because of language, culture, not understanding how the system works and constant change of residency place. Therefore, being open to referrals from services other than primary or secondary healthcare services is important for guaranteeing access for this population. We provide consultations in different languages, schedule first appointments promptly, and keep close contact with the institutions providing aid for migrants and refugees.

The majority of patients stayed in the service for fewer than three months, and the vast majority were drop outs. Professionals usually report that the relatively short duration of treatment was due to socioeconomic barriers (e.g., no money for transportation). However, in our study, unemployment and living in temporary housing were not associated with treatment duration. These categories might not be good measures for socioeconomic disadvantage experienced by this population, but these data can also indicate that structural barriers might not be the most important barriers in this case. We need to raise new hypotheses for understanding treatment adherence, considering language barriers, cultural barriers, doctor-patient relationships and stigma of mental illness.

\section{Closing Remarks}

Providing healthcare for immigrants and refugees brings particular challenges. In Brazil, this discussion is quite recent due to an increase in international migration in the last decade. Refugees and asylum seekers should be considered a highly vulnerable group, and they have poorer mental health outcomes. This growing group is gaining attention in Brazil, raising questions on how to provide better life conditions that would help their integration and improve mental health as well as how to provide adequate health care.

Services that provide care for this population must not only develop their own strategies to guarantee access but also overcome language and cultural barriers. In mental health, some barriers might be harder to overcome than in general healthcare, given the central role of language for a proper psychiatric evaluation and the fact that mental illnesses might be explained by different and sometimes conflicting culturally variable models (religious, environmental, psychological, biological, etc.). 


\section{Limitations and future research}

The present study used a retrospective observational design with an exploratory statistical framework and shed light on potential associations to be further explored in specifically designed prospective studies. The sample was selective, and the methodology was exclusively quantitative; therefore, the results are mostly descriptive. Qualitative studies would be useful to investigate the personal experiences of this population and how they impact their mental health. A qualitative study should be designed to address questions about service compliance and adherence, which would improve understanding of the actual barriers to care in our specific setting. Critically, no causal inferences can be drawn, and no generalizations can be made. Though covering an extended period of time, we had a relatively small sample. However, it is important to emphasize the lack of quality data on the mental health of immigrants and refugees living in countries from the Global South and the expected growth of service demands in these settings. Future investigations using combinations of qualitative methodology and hypothesis-driven analysis are warranted to further understand the barriers to care, reasons to seek help for mental health needs, concepts of adequate care, explanatory models for mental illness and the most influential factors in recovering from mental illnesses among the particularly vulnerable populations of migrants and refugees in the Global South.

\section{Footnote}

A. The term "Global North" refers to high-income countries in Europe, North America and Oceania. It is a consequence for the preference of use of the term "Global South" in Social Sciences to refer to regions of Latin America, Asia, Africa and Oceania, to countries that were called "Third World" or "underdeveloped". The choice of using these terms to characterize differences between countries shifts the focus from development or cultural differences to geopolitical relations of power. ${ }^{2}$

\section{Abbreviations}

CONARE: Comitê Nacional para Refugiados (Brazilian Committee for Refugees)

CRRC: Caritas Refugee Reference Center

DRC: Democratic Republic of Congo

ICD-10: International Classification of Diseases, $10^{\text {th }}$ edition

NGO: non-governmental organization

ProSol: Programa de Psiquiatria Social e Cultural (Program of Social and Cultural Psychiatry)

PTSD: Post-traumatic stress disorder

SUS: Sistema Unico de Saude (Unified Health System)

UNHCR: United Nations High Commissioner for Refugees

\section{Declarations}

\section{Ethics approval and consent to participate}

Ethical approval for the present study and data collection was granted by the Hospital das Clínicas from Universidade de São Paulo Ethics Committee (ID 2.126.447) 


\section{Consent for publication}

Not applicable

\section{Availability of data and materials}

The datasets used and/or analyzed during the current study are available from the corresponding author upon reasonable request.

\section{Competing interests}

All authors declare they have no competing interests.

\section{Funding}

The study was part of the project "M3 - Mental Health, Migration and the Megacity (São Paulo)" funded by FAPESP (process number: 2016/50307-3)

\section{Authors' contributions}

LAC analyzed and interpreted the data, being a major contributor in writing the article. LHA contributed to the data analysis and final revision. PLA performed the data collection and helped with the written part of the analysis. CLAS made substantial contributions to the study's conception, design and final revision. PVA contributed to data analysis and conception. FLN contributed to writing and revising the manuscript. CEB contributed to the data analysis, writing and final revision. All authors read and approved the final manuscript.

\section{Acknowledgements}

Not applicable

\section{References}

1. United Nations - Sustainable development goals. https://www.un.org/sustainabledevelopment/blog/2016/01/244million-international-migrants-living-abroad-worldwide-new-un-statistics-reveal/. Accessed 14 Feb 2020.

2. Dados N, Connell R. The Global South. Contexts. 2012;11(1):12-13.

3. International Organization for Migration. Global Migration Trends Fact Sheet. http://gmdac.iom.int/global-migrationtrends-factsheet. Accessed 14 Feb 2020.

4. United Nations High Commissioner for Refugees. Global Trends - Forced Displacement in 2018. https://www.unhcr.org/5d08d7ee7.pdf. Accessed 14 Feb 2020.

5. Instituto Brasileiro de Geografia e Estatística. Censo Demográfico 1940-2010. http://seriesestatisticas.ibge.gov.br/series.aspx?vcodigo=POP122. Accessed 14 Feb 2020.

6. Observatório das Migrações Internacionais. Sistema Nacional de Cadastramento de Registro de Estrangeiros (SINCRE) Base de dados 2015. http://obmigra.mte.gov.br/index.php/anuarios. Accessed 14 Feb 2020. 
7. Velasco C, Mantovani F. Em 10 anos, número de imigrantes aumenta 160\% no Brasil, diz PF. Portal G1. 25 de junho de 2016. http://g1.globo.com/mundo/noticia/2016/06/em-10-anos-numero-de-imigrantes-aumenta-160-no-brasil-dizpf.html. Accessed 14 Feb 2020.

8. SECRETARIA NACIONAL DE JUSTIÇA (SNL), Ministério da Justiça e Segurança Pública. Refúgio em números - 3a. edição. 2017. http://www.justica.gov.br/news/de-10-1-mil-refugiados-apenas-5-1-mil-continuam-no-brasil/refugio-emnumeros_1104.pdf/view. Accessed 14 Feb 2020.

9. SECRETARIA NACIONAL DE JUSTIÇA (SNL), Ministério da Justiça e Segurança Pública. Refúgio em números - 4a. edição. 2019. https://www.justica.gov.br/seus-direitos/refugio/refugio-em-numeros. Accessed 14 Feb 2020.

10. United Nations High Commissioner for Refugees. Novo perfil do refúgio no Brasil - Novembro de 2014. https://www.acnur.org/fileadmin/Documentos/portugues/Estatisticas/Refugio_no_Brasil_2010_2014_Apresentacao.pdf? view=1. Accessed 14 Feb 2020.

11. Lei no. 9.474, de 22 de julho de 1997. Define mecanismos para a implementação do Estatuto dos Refugiados de 1951, e determina outras providências. Diário Oficial da União. 23 jul 1997, p. 15822

12. SECRETARIA NACIONAL DE JUSTIÇA (SNL), Ministério da Justiça e Segurança Pública. Refúgio em números. 2016. http://www.justica.gov.br/news/brasil-tem-aumento-de-12-no-numero-de-refugiados-em-2016/20062017_refugio-emnumeros-2010-2016.pdf. Accessed 14 Feb 2020.

13. Banco interativo da Migrações em São Paulo. https://www.nepo.unicamp.br/publicacoes/bancointerativo.html. Accessed 21 Feb 2020.

14. Ryan L, Leavey G, Golden A, Blizard R, King M . Depression in Irish migrants living in London: case-control study. Br J Psychiatry. 2006;188:560-6.

15. Laban CJ, Komproe IH, Gernaat HB, de Jong JT. The impact of a long asylum procedure on quality of life, disability and physical health in Iraqi asylum seekers in the Netherlands. Soc Psychiatr Epidemiol. 2008;43(7):507-15.

16. Hvidtfeldt C, Petersen JH, Norredam M. Prolonged periods of waiting for an asylumdecision and the risk of psychiatric diagnoses: a 22-year longitudinal cohort study from Denmark. Int J Epidemiol. 2019; May 18. [Epub ahead of print]

17. Nickerson A, Byrow Y, O'Donnell M, Mau V, McMahon T et al. The association between visa insecurity and mental health, disability and social engagement in refugees living in Australia. Eur J Psychotraumatol. 2019;10(1).

18. Fazel M, Wheeler J, Danesh J. Prevalence of serious mental disorder in 7000 refugees resettled in western countries: a systematic review. Lancet. 2005;365(9467):1309-14.

19. Porter M, Haslam N. Predisplacement and postdisplacement factors associated with mental health of refugees and internally displaced persons: a meta-analysis. JAMA. 2005;294(5):602-12.

20. Søegaard EGI, Kan Z, Koirala R, Hauff E, Thapa SB. Variations in psychiatric morbidity between traumatized Norwegian, refugees and other immigrantpatients in Oslo. Nord J Psychiatry. 2020;21:1-10.

21. Hollander AC. Social inequalities in mental healthand mortality among refugees and other immigrants to Swedenepidemiological studies of register data. Glob Health Action. 2013;6.

22. Silove D, Steel Z, McGorry P, Mohan P. Trauma exposure, postmigration stressors, and symptoms of anxiety, depression and post-traumatic stress in Tamil asylum-seekers: comparison with refugees and Acta Psychiatr Scand. 1998; 97(3):175-181.

23. Steel Z, Chey T, Silove D, Marnane C, Bryant RA, van Ommeren M. Association of torture and other potentially traumatic events with mental health outcomes among populations exposed to mass conflict and displacement: a systematic review and meta-analysis. JAMA. 2009;302(5):537-49.

24. Kirmayer LJ, Narasiah L, Munoz M et al. Common mental health problems in immigrants and refugees: general approach in primary care. CMAJ. 2011;183:1-9.

25. Morgan C, Knowles G, Hutchinson G. Migration, ethnicity and psychoses: evidence, models and future directions. World Psych. 2019;18:247-58. 
26. Kirkbride JB, Errazruiz A, Croudace TJ, Morgan C, Jackson D, Boydell J, Murray RM, Jones PB. Incidenceof schizophrenia and other psychoses in England, 1950-2009:a systematic review and meta-analyses. PLOS One. 2012;7(3):e31660.

27. Freedman J. (2016) Sexual and gender-based violence against refugee women: a hidden aspect of the refugee "crisis". Reproductive Health Matters. 2016;24(47):18-26.

28. Piccinelli M, Wilkinson G. Gender differences in depression: Critical review. Br J Psychiatry. 2000;177:486-92.

29. Hapke U, Schumann A, Rumpf HJ, John U, Meyer C. Post-traumatic stress disorder - The role of trauma, pre-existing psychiatric disorders, and gender. Eur Arch Psychiatry Clin Neurosci. 2006;256(5):299-306.

30. Carta MG, Bernal M, Hardoy MC, Haro-Abad JM. Migration and mental health in Europe (the state of the mental health in Europe working group: appendix 1). Clin Pract Epidemol Ment Health. 2005;1:13.

31. Blight KJ, Ekblad S, Persson JO, Ekberg J. Mental health, employment and gender. Cross-sectional evidence in a sample of refugees from Bosnia-Herzegovina living in two Swedish regions. Soc Sci Med. 2006;62(7):1697-1709.

32. Hollander AC, Bruce D, Burstrom B, Ekblad S. Gender-related mental health differences between refugees and non-refugee immigrants- a cross-sectional register-based study. BMC Public Health, 2011, 11:180

33. Constituição (1988). Artigos 196 a 200. Brasília: Diário Oficial da União; 1988.

34. Castro MC, Massuda A, Almeida G, Menezes-Filho NA et al. Brazil's unified health system: the first 30 years and prospects for the future. Lancet. 2019;394:345-56.

35. Santana CLA, Lotufo Neto F. Developing a mental health programme for refugees based on participatory Action Research: An experience from São Paulo, Brazil. International Journal of Action Research. 2016;11(3):265-88.

36. Shawyer F, Enticott JC, Block AA, Cheng I, Meadows GN. The mental health status of refugees and asylum seekers attending a refugee health clinic including comparisons with a matched sample of Australian-born residents. BMC Psychiatry. 2017; 17:76.

37. Pfortmueller CA, Graf F, Tabarra M, Lindner G, Zimmermann H, Exadaktylos AK. Acute Health Problems in African Refugees - Ten years' experience in a Swiss emergency department. Wien Klin Wochenschr. 2012;124:647-52.

38. Santana CLA, Lotufo Neto F. Psicodinâmica e Cultura: a implantação de um programa de saúde mental para refugiados em São Paulo. In: DeBiaggi SD, editor. Psicologia, e/imigração e cultura. São Paulo: Casa do Psicólogo. p.165-190.

39. Levahot K, Beckman KL, Chen JA, Simpson TL. Williams EC. Race/Ethnicity and sexual orientation disparities in mental health, sexism, and social support among women veterans. Psychol Sex Orientat Gend Divers. 2019;6(3): 347-58.

40. Branco Pereira A. The trauma refuge. Ethnographic notes about trauma, racism and suffering temporalities in a mental health service for refugees. REMHU, Rev. Interdiscip. Mobil. Hum. 2018;26(53):79-97.

41. Turrini G, Purgatp M, Ballette F, Nosè M, Ostuzzi G, Barbui C. Common mental disorders in asylum seekers and refugees: umbrella review of prevalence and intervention studies. Int J Ment Health Syst. 2017;11(51).

42. Böttche M, Heeke C, Knaevelsrud C. Sequential traumatization, trauma-related disorders and psychotherapeutic approaches in war-traumatized adult refugeesand asylum seekers in Germany. Bundesgesundheitsblatt Gesundheitsforschung Gesundheitsschutz. 2016;59(5):621-6.

43. Kirkbride JB, Jones PB. Epidemiological aspects of migration and mental illness. In: Bhugra D, Gupta S, editors. Migration and Mental Health. Cambridge: Cambridge University Press; 2011.15-45.

44. Cantor-Graae E, Selten JP. Schizophrenia and migration: a meta-analysis and review. Am J Psyc 2005;162(1):12-24.

\section{Figures}



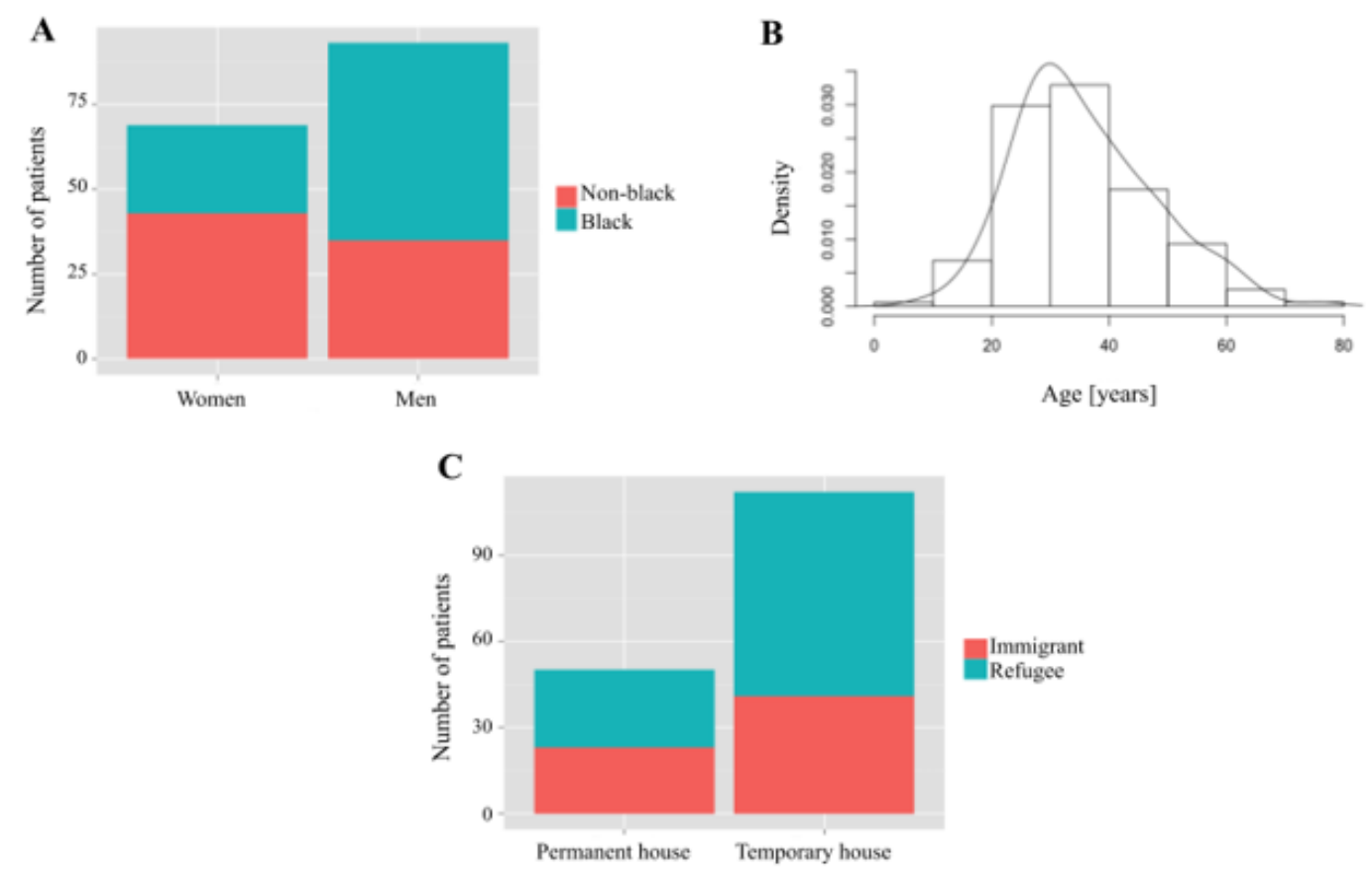

\section{Figure 1}

Demographic profile of all immigrant and refugee patients attending the ProSol outpatient service from 2003 to 2018 . A - Sex and skin color distribution evidencing a majority of Black men in the service; B - Histogram of distribution of ages at first appointment, with most patients in the third or fourth decade of life; $\mathrm{C}$ - Housing conditions (permanent or temporary) according to migratory status.

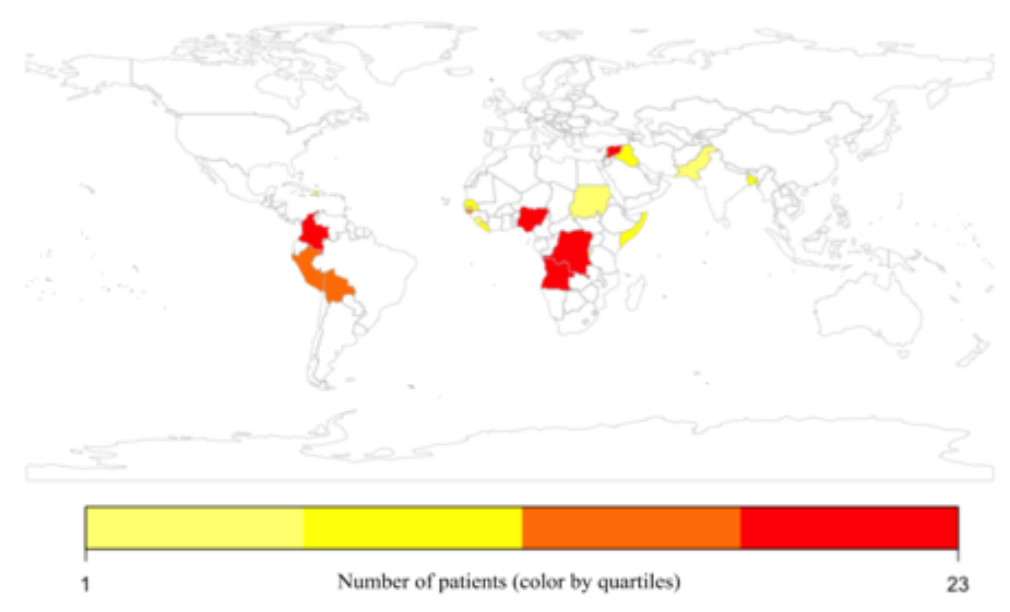

\section{Figure 2}

Map of countries of origins. The color scale refers to quartiles of distribution. Note that the vast majority of patients emigrate from West-Coast African and South American countries. 


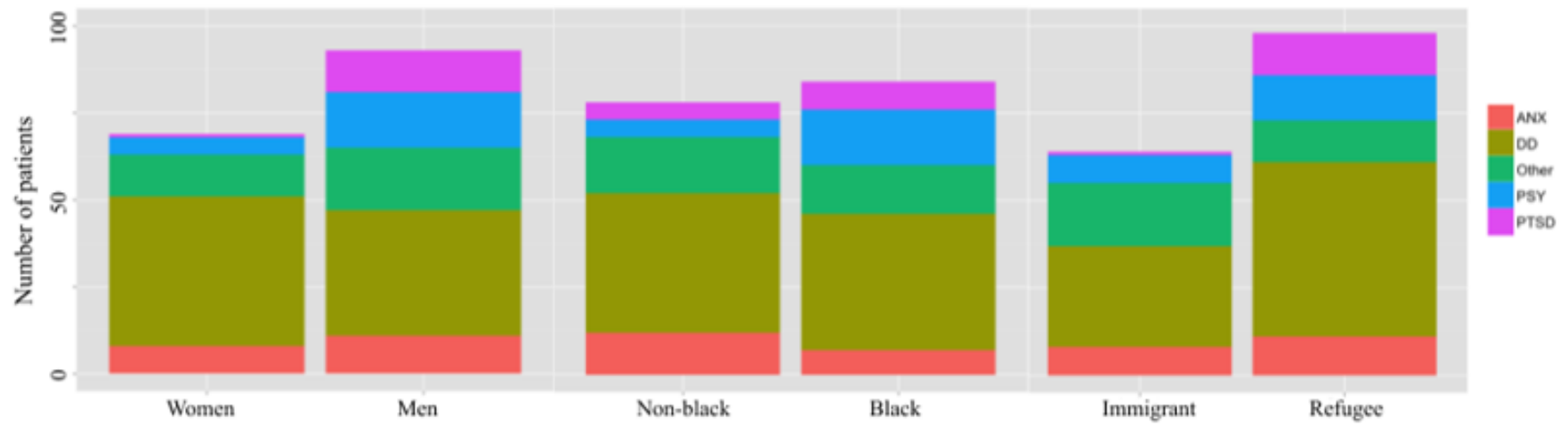

\section{Figure 3}

Profile of primary ICD-10-based psychiatric diagnoses of all immigrant and refugee patients. In agreement with global prevalence, depressive disorder corresponds to approximately half of the diagnoses. Note the increased prevalence of psychotic disorders and PTSD in Black men in relation to women. Regarding migratory status, increased prevalences of depressive disorders and PTSD were observed for refugees compared with non-refugee immigrants. ANX: anxiety disorders; DD: depressive disorders; PSY: psychotic disorders; PTSD: post-traumatic stress disorder.
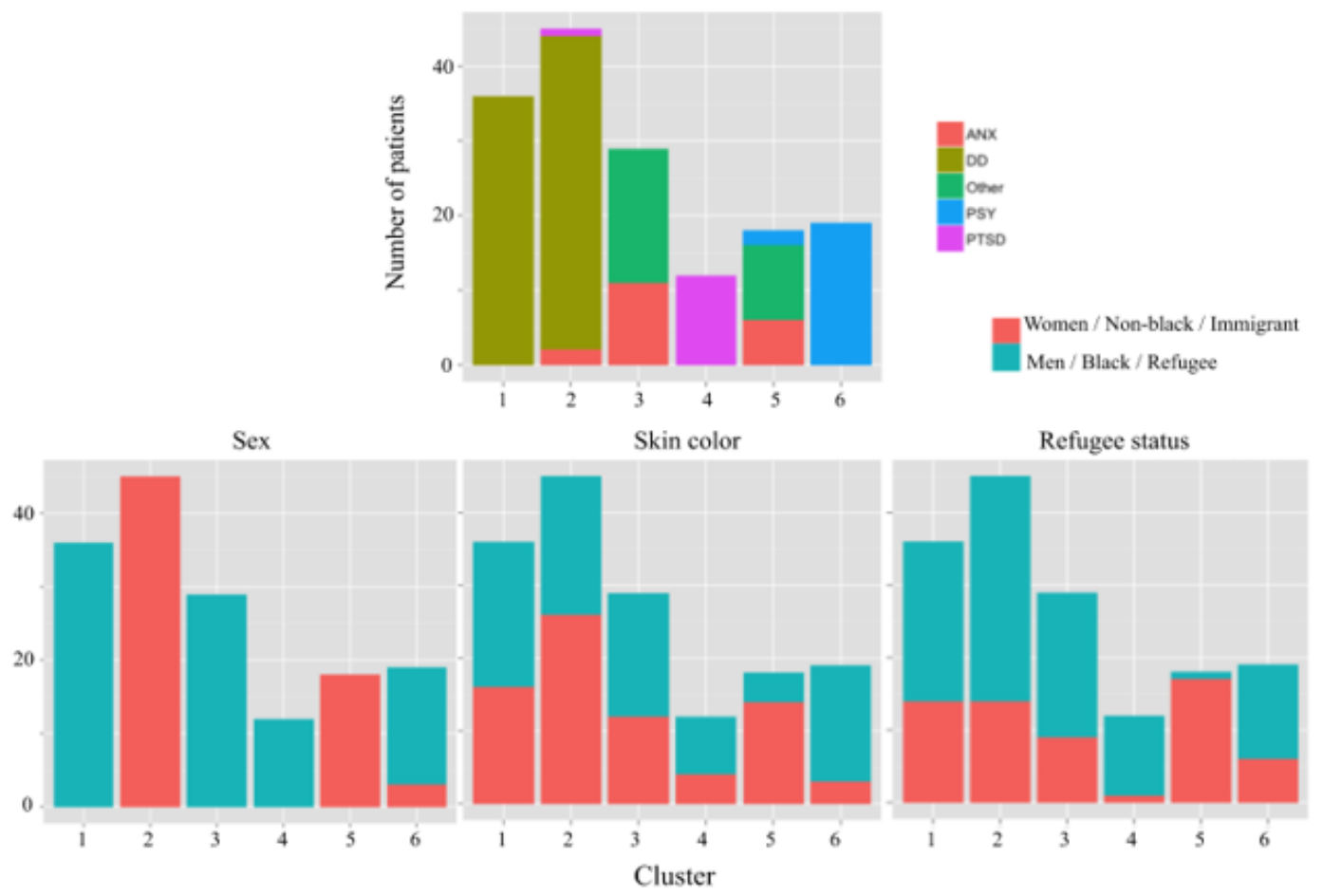

\section{Figure 4}

Results of cluster analysis. Clusters 1 and 2 comprise men and women diagnosed with depressive disorders, respectively. Clusters 3 and 5 include patients with anxiety disorders or other ICD-10 diagnoses (e.g., obsessive compulsive disorder, somatoform disorders) but with fewer than three patients in the sample. Cluster 4 includes patients with PTSD, and cluster 6 includes patients with psychotic disorders, which were mainly Black refugee men. ANX: anxiety disorders; DD: depressive disorders; PSY: psychotic disorders; PTSD: post-traumatic stress disorder. 